\title{
OVERVIEW OF PYREXIA
}

Fever: Basic Mechanisms and Management, edited by Philip A Mackowiak (1991). Raven Press Ltd, 1185 Avenue of the Americas, New York, NY 10036, USA. 366 pages;US\$90.

It was with some trepidation that I opened the cover of this 366-page text. expecting a painfully long description of the complex molecular and physiological mechanisms for pyrexia. To my surprise I discovered that this text covers the basic mechanisms of thermogenesis, including the role of cytokines and prostaglandins, as well as thermometry, fever patterns, adaptive cardiovascular and immunological responses to fever and then switches gears to cover the clinical topics of fever of unknown origin, fever in the immunocompromised patient, the young patient and the elderly patient. It even takes on the topies of drug fever, heat stroke and hypothermia.

The first 10 chapters cover the physiology and molecular basis for pyrexia and thermoregulation. I parlicularly enjoyed the chapter on clinical thermometry which documents the history and validity for lack thereof!) of our methods for temperature measurement. The second half of the book covers the clinical topics. These are covered fairly superficially as onc might expect for such a broad entity as fever.

I have a few criticisms of this text. First and foremost. unfortunately the authors switch from the Celsius to Fahrenheit system and because of their lack of consistency, their descriptive chapters - especially on fever patterns and temperature measurement - are disjointed and difficult to follow. Secondly, the figures are 
not all clear and coneise, especially the poor reproductions of fever patterns in Chapter 6 . Finally. tables of causes of fever which list 'miscellaneous' at the top of the list are unhelpful.

It is commendable to attempt a broad text on fever and hyperpyrexia but in their quest for completeness I am left wondering who would benefit most from reading this text. Certainly the generalist with an interest in infectious diseases would find the clinical chapters interesting but the basic science chapters are more oriented towards a subspecialist or the researcher. In general the clinical chapters are well-written although fairly basic for anyone with experience in infectious diseases. The basic science chapters give a more detailed account of this rapidly changing field. I would recommend this book with the abovementioned caveats.

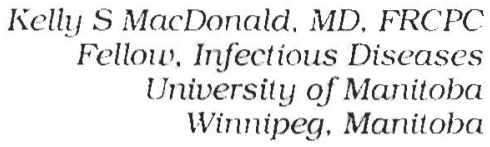




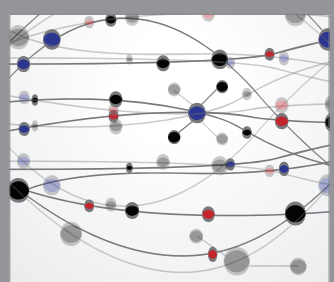

The Scientific World Journal
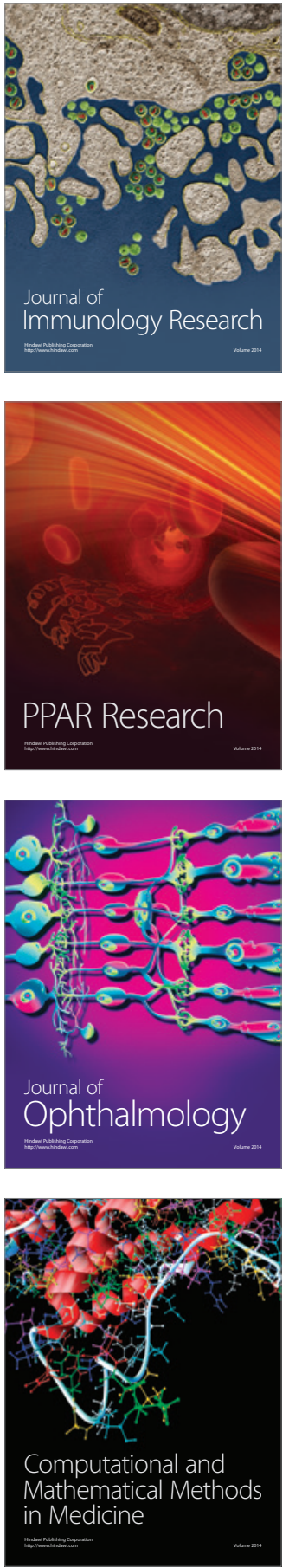

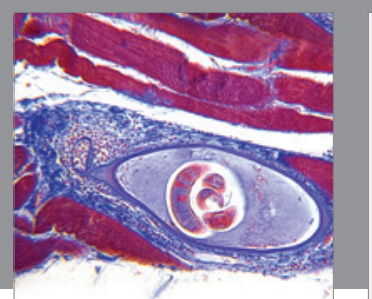

Gastroenterology Research and Practice

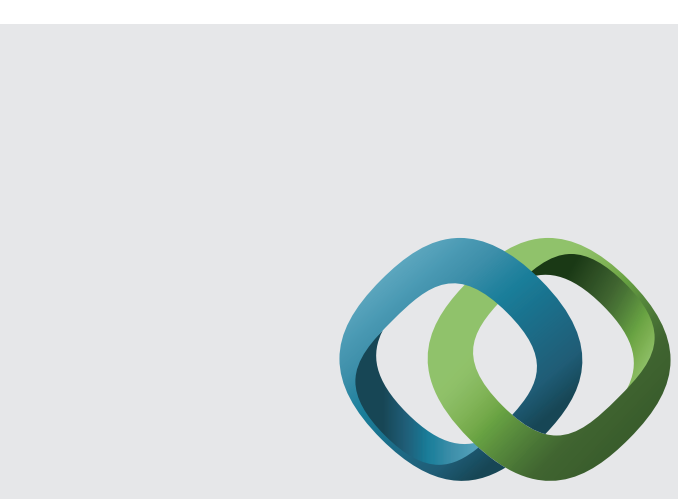

\section{Hindawi}

Submit your manuscripts at

http://www.hindawi.com
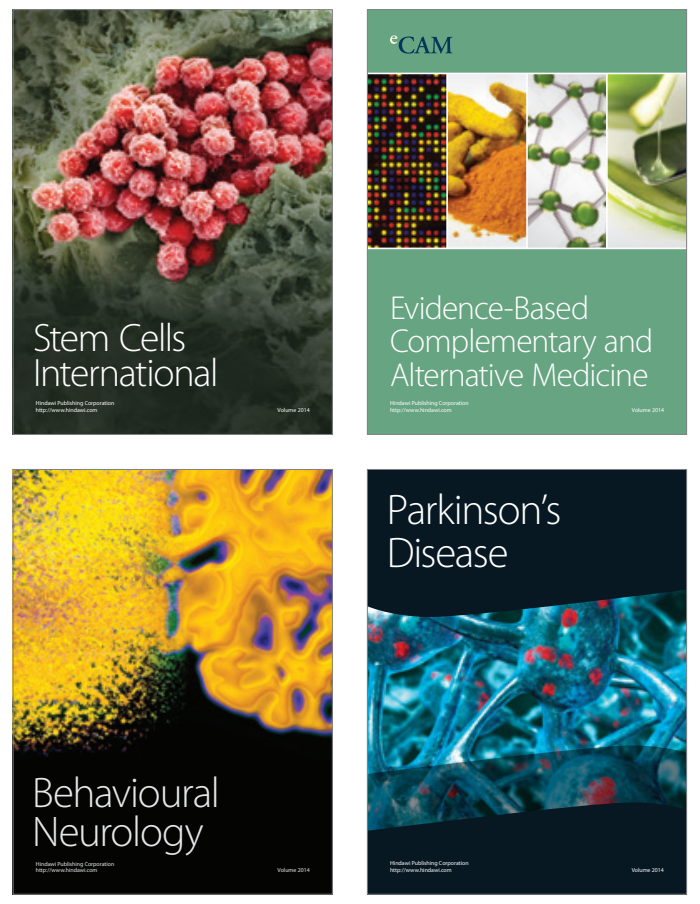
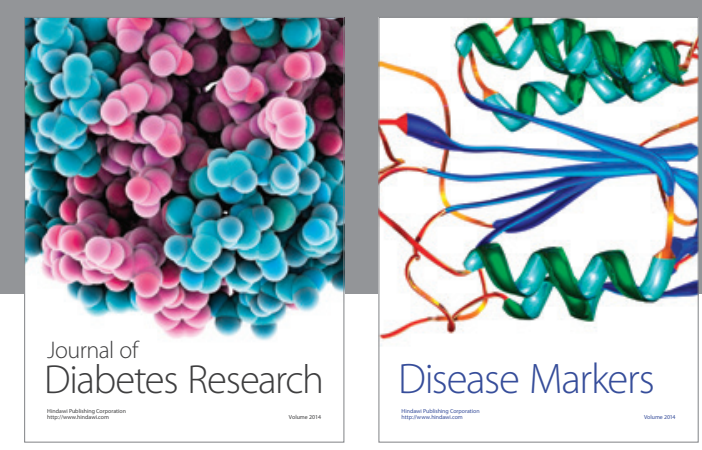

Disease Markers
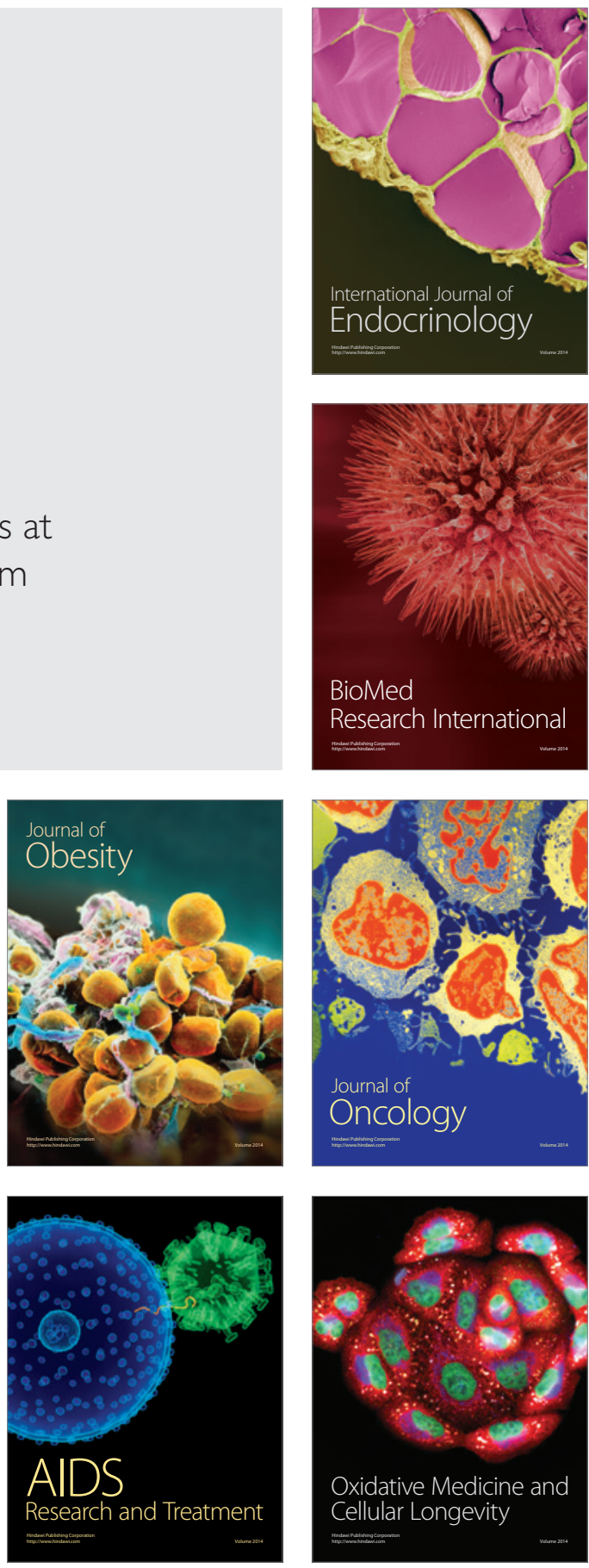